\title{
Deep-seated Hibernoma of Thigh: A Rare Benign Adipocytic Tumor
}

\author{
Muhammad Omar Afzal, Ata-ul-Haq, Sobia Mazhar and Moazzam Nazeer Tarar \\ Jinnah Burn and Reconstructive Surgery Center, Lahore, Pakistan
}

\begin{abstract}
Hibernoma is a rare benign soft tissue adipocytic tumor. Mostly found in adults, it is usually located in the limbs, and is deepseated or intramuscular. Usually asymptomatic, it causes symptoms when it becomes large enough to compress adjacent structures, mimicking well differentiated liposarcoma clinically and radiologically. We present a case report of a deepseated hibernoma of thigh. Radiological investigation and incisional biopsy were done to diagnose and define the surgical roadmap to completely excise it. We describe our technique to precisely control feeding vessels and meticulous dissection to preserve thigh muscles to retain function.
\end{abstract}

Key Words: Hibernoma, Benign tumor, Thigh.

How to cite this article: Afzal MO, Haq AU, Mazhar S, Tarar MN. Deep-seated hibernoma of thigh: a rare benign adipocytic tumor. $J$ Coll Physicians Surg Pak 2019; 29(Supplement): S117-S119.

\section{INTRODUCTION}

Hibernoma is a rare benign tumor and thought to arise from remnants of brown adipose tissue of fetal origin. It is found both at regions where the brown fat may persist beyond fetal life or it is absent in adults. ${ }^{1}$ Usually asymptomatic and slow growing, it may cause pressure symptoms, if large. Clinically and radiologically, it is often confused with soft tissue sarcomas. Due to its hypervascularity, it presents itself as a challenge to the operating surgeon, particularly, if deepseated. We present our experience with a case presenting with swelling of thigh, and the technique for complete excision with control of feeding vessels.

\section{CASE REPORT}

A 26-year male presented with swelling over upper and medial aspect of right thigh for last one year. Insidious in onset, it increased progressively since the patient noticed it while changing clothes. It was associated with discomfort during activity, particularly during walking and in squat. There was no history of pain, numbness and weakness of right lower limb, together with systemic complaints.

The swelling was ovoid with smooth surface and located in anteromedial aspect of right upper and mid thigh and measured $28 \times 18 \mathrm{~cm}$. There was a scar of core biopsy over it. It was mildly tender, comparatively warmer with firm consistency. It was immobile and deep to anterior compartment muscles of thigh. Fluctuation, transallumination, slip sign and thrill were not present. It did

Correspondence to: Dr. Muhammad Omar Afzal, Jinnah Burn and Reconstructive Surgery Center, Lahore, Pakistan

E-mail:omarafzal22@hotmail.com

Received: May 06, 2019; Revised: July 18, 2019;

Accepted: July 27, 2019 not increase in size or become tense on dependency and there was no emptying. Distal neurovascular status was intact, but there was decreased active and passive flexion at knee joint with $4 / 5$ knee extension according to medical research council (MRC) scale. There was difficulty in gait with patient walking with slightly abducted lower limbs. There was no lymphadenopathy. Abdominal and systemic examination was unremarkable. Core biopsy had been done elsewhere, which was inconclusive.

Incisional biopsy at the site of core biopsy was done after contrast-enhanced magnetic resonance imaging (MRI). We tattoed the site for future reference, as well. Histopathologically, diagnosis of hibernoma was made. We then planned excision of the lesion with proximal and distal control of the vessels, by taking guidance from radiological investigations. Figure 1 summarises MRI and doppler ultrasound findings.

An s-shaped incision was made with marking incorporating the scar of incisional biopsy within the resected tissue. Dissection was first done medially and feeding vessels from superficial femoral vessels were isolated and control was taken by passing feeding tube around superficial femoral vessels, working as a safety valve. There were many small vessels, with a larger one in the proximal pole of the tumor. All were ligated with the help of vascular clips which have less chances of slippage. Small vessels were cauterized with bipolar cautry. Dissection was then done over the tumor with careful separation of the muscles with the help of blunt scissors and fingers, developing a plane between rectus femoris and vastus medialis. Wide and fragile venous channels were found draining the tumor at its lower pole into the descending branch of profunda femoral vessel. Under gentle traction, distal control and careful ligation of vessels, tumor was removed with intact capsule. 


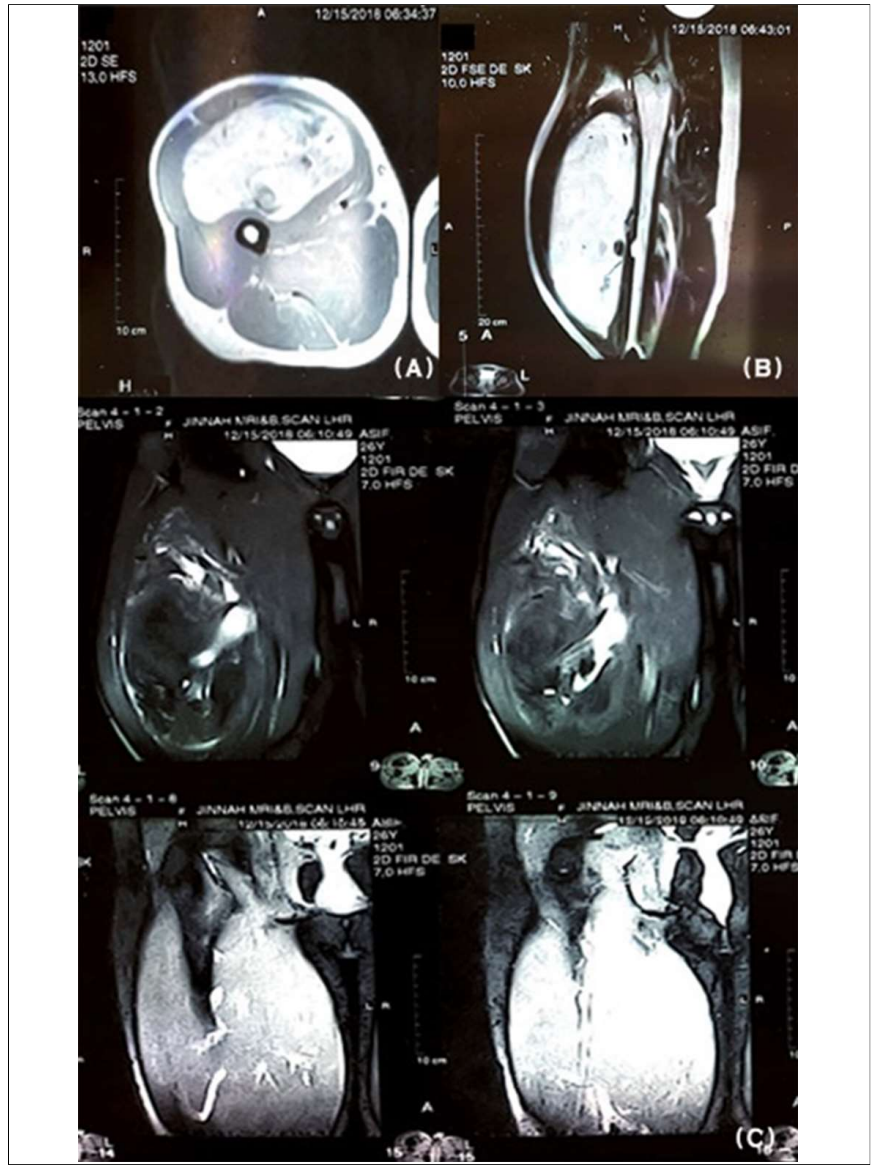

Figure 1: (A) A1W1 image shows an intramuscular lesion that is hyperintense but slightly hypotense to the surrounding subcutaneous fat. (B) T2W1 image shows a well defined hyperintense lesion with flow voids of feeding vessels. (C) FATSAT image shows incomplete supression of fat due to hetrogenous content of the lesion and relatively decreased amount of lipid compared to the adipose tissue. The flow voids represent vessels and slow flow.

Haemostasis was secured and wound was closed in layers over a suction drain. Although haemoglobin dropped from 13.5 to $11.4 \mathrm{~g} / \mathrm{dl}$ after the procedure, no transfusion was needed. Drain was kept for 1 week owing to large volume of serosanguinous fluid in the range of $200 \mathrm{ml}$. Patient was discharged with compression garment over thigh and there was no complication on follow-up. Figure 2 shows steps of dissection, with control of large feeding vessels.

\section{DISCUSSION}

Hibernoma is a rare benign soft tissue tumor, accounting for about $1 \%$ of all excised lipomas, and only rarely deepseated.2 It is mostly located in limbs, thigh being the most predominant region, followed by neck, back and axilla. ${ }^{2}$ Patients mostly present in $3^{\text {rd }}$ or $4^{\text {th }}$ decades of life with slight predominance in females. ${ }^{2}$ Histologically, there are 4 variants, i.e, typical, lipoma-like, myxoid and spindle cell type. ${ }^{3}$ Although initially thought to arise from brown fat, its scarcity in children has led to it being described as benign adipocytic tumor with differentiation similar to brown fat and not as arising from the brown

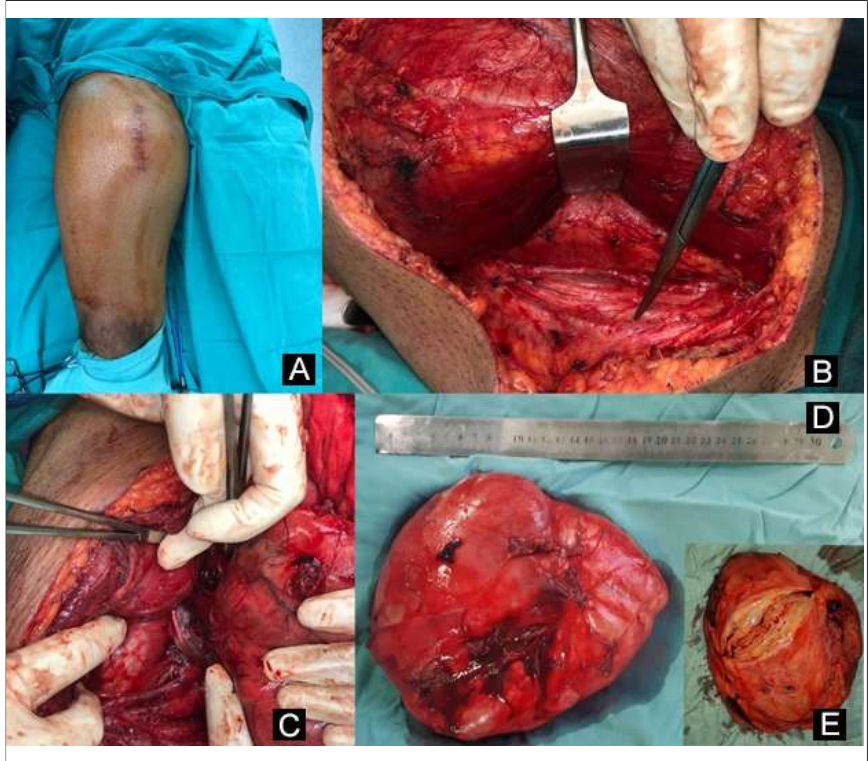

Figure 2: (A) Image shows a large swelling over anteromedial aspect of right upper thigh. (B) Superficial femoral artery is visible with legated multiple small feeding branches. (C) Large fragile draining vein is draining into descending branch of lateral circumflex femoral vessles. (D) A well encapsulated lesion of about $21 \mathrm{~cm}$ in length. (E) Cut surface of the lesion.

fat. ${ }^{4}$ Although immunohistochemistry is not contributory, they are usually positive for S-100 protein. Hibernomas are mostly CD-34 negative and always negative for CDK4 and MDM2, markers that identify welldifferentiated liposarcoma. 5 On MRI, they are well circumscribed, hyperintense on T1-weighted, mostly hypointense and rarely hyper or isointense on T 2-weighted images. They show heterogeneous enhance-ment on contrast images, with large flow voids in the tumor. 6 They typically present as slow growing, progressive and painless soft-tissue swellings, rarely with localised tenderness. ${ }^{7}$ Symptoms appear when they start compressing adjacent structures. ${ }^{7}$ Rarely, there is significant weight loss, which is attributed to excessive thermogenesis by the tumor cells. ${ }^{7}$ Complete excision with preservation of adjacent structures is the curative treatment. Meticulous control of feeding vessels is mandatory to avoid complications. Rarely, incomplete excision results in recurrence.

\section{PATIENT'S CONSENT:}

Infromed written consent was taken from the patient before study was approved by Ethical Review Committee.

\section{CONFLICT OF INTEREST:}

Authors declared no conflict of interest.

\section{AUTHORS' CONTRIBUTION:}

MOA, AUH: Principle surgeons who operated.

SM: Radiologist, involved in planning the surgical roadmap.

MNT: Overall helped in planning. 


\section{REFERENCES}

1. Honoki K, Morita K, Kasai T, Fujii H, Kido A, Tsukamoto S, et al. Hibernoma of the axillary region: A rare benign adipocytic tumor. Rare Tumors 2010; 2:e7.

2. Furlong MA, Fanburg-Smith JC, Miettinen M. The morphological spectrum of hibernoma. A clinicopathologic study of 120 cases. Am J Surg Pathol 2001; 25:809-14.

3. Miettinen MM, Fanburg-Smith JC, Mandahl N. Hibernoma. In: Fletcher CDM, Unni KK, Mertens F, Eds. WHO classification of tumours. Pathology and genetics of tumours of soft tissue and bone. Lyon (France): IARC Press; 2002. p. 33-4.
4. Vassos N, Lell M, Hohenberger W, Croner RS, Agaimy A. Deep-seated huge hibernoma of soft tissue: A rare differential diagnosis of atypical lipomatous tumor/well differentiated liposarcoma. Int J Clin Exp Pathol 2013; 6:2178-84.

5. Levine GD. Hibernoma. An electron microscopic study. Hum Pathol 1972; 3:351-9.

6. Kovitwanichkanont T, Naidoo P, Guio-Aguilar P, Leong J. Hibernoma: A rare benign soft tissue tumour resembling liposarcoma. BJR Case Rep 2018; 4:20170067.

7. Essadel A, Bensaid Alaoui S, Mssrouri R, Mohammadine E, Benamr S, Taghy A, et al. L'Hibernome: une rare cause d'amaigrissement massif. Ann Chir 2002; 127:215-7.

$\cdots \cdots$ 